\title{
Algoritma K-Means dalam Pemilihan Siswa Berprestasi dan Metode SAW untuk Prediksi Penerima Beasiswa Berprestasi
}

\author{
Rini Sovia ${ }^{\# 1}$, Eka Praja Wiyata Mandala ${ }^{\# 2}$, Sitty Mardhiah ${ }^{\# 3}$, \\ \# Teknik Informatika, Ilmu Komputer, Universitas Putra Indonesia "YPTK” Padang \\ Jalan Raya Lubuk Begalung, Padang \\ 1rini sovia@upiyptk.ac.id \\ ekaprajawm@upiyptk.ac.id \\ ${ }^{3}$ dhiahmsitty@gmail.com
}

\begin{abstract}
Abstrak - Beasiswa prestasi merupakan beasiswa yang diberikan kepada siswa berprestasi di sekolah agar dapat memberikan motivasi lebih giat dalam belajar. Namun, pemberian beasiswa sering tidak tepat sasaran dan ketersediaan dana beasiswa yang terbatas membuat banyak siswa yang berprestasi tidak dapat memperolehnya sehingga siswa yang berprestasi akan turun semangatnya untuk terus belajar. Agar lebih mudah dalam memilih siswa berprestasi, maka diperlukan pendekatan data mining untuk mengelompokkan siswa berprestasi dengan menggunakan Algoritma K-Means dan selanjutnya bisa dibuat sistem pendukung keputusan untuk melakukan perangkingan dengan metode Simple Additive Weighting $(\mathrm{SAW})$ dari siswa berprestasi yang sudah dikelompokkan sehingga akan diperoleh siswa yang berprestasi yang berhak menerima beasiswa. Penelitian ini menggunakan 5 kriteria yaitu nilai rata-rata siswa, peringkat, nilai sikap, nilai ekstrakurikuler dan prestasi akademik maupun non akademik. Penelitian dilakukan di SMAN 2 Payakumbuh. Ada 20 data siswa yang mengajukan beasiswa digunakan dalam penelitian ini. Hasil penelitian ini dengan menggabungkan K-Means dan SAW, ternyata dapat mempermudah proses pengelompokkan data siswa berprestasi dan penetuan prediksi penerima beasiswa berprestasi karena lebih cepat dan lebih tepat sasaran. Dari 20 data siswa yang mengajukan beasiswa, dikelompokkan menjadi 10 siswa yang berprestasi dan dilakukan perangkingan sehingga hanya 6 siswa yang berhak menerima beasiswa.
\end{abstract}

Kata kunci- Prediksi, Siswa Berprestasi, Beasiswa Berprestasi, K-Means, SAW

\section{Pendahuluan}

Dana beasiswa yang akan diberikan kepada siswa berprestasi seringkali terbatas sehingga tidak mencukupi untuk diberikan kepada seluruh siswa yang ingin mendapatkan beasiswa, dan kadang pemberian beasiswanya tidak tepat sasaran. Untuk itu dipilihlah beberapa siswa yang benar benar layak untuk diberikan beasiswa. Karena banyaknya siswa yang mengurus beasiswa dan sudah memenuhi persyaratan namun pihak sekolah membutuh waktu untuk menentukan siswa mana yang layak mendapatkan beasiswa. Masalah seperti ini dihadapi oleh SMAN 2 Payakumbuh.

Penelitian ini dilakukan dengan tujuan untuk membantu pihak sekolah dalam mengelompokkan siswa yang berprestasi di sekolah kemudian dapat melakukan prediksi dalam menentukan siswa yang berhak memperoleh beasiswa berprestasi.

Pendidikan memiliki peran yang amat penting dalam masyarakat karena pendidikan merupakan upaya untuk memperbaiki taraf hidup manusia. Hal ini dijelaskan dalam UU No.20/2003 mengenai pendidikan yang menyatakan bahwa pendidikan merupakan usaha sadar dan terencana untuk menimbulkan suasana belajar serta proses pembelajaran supaya peserta didik dapat secara aktif dalam pengembangan potensi diri [1].

Data mining dapat diartikan sebagai proses ekstraksi informasi baru yang diperoleh dari bongkahan data yang besar untuk membantu dalam mengambil keputusan. Istilah data mining dapat juga disebut knowledge discovery [2]. Sistem pendukung keputusan adalah sistem dengan basis komputer untuk pengambilan keputusan untuk menangani masalah-masalah semi terstruktur [3].

Berdasarkan penelitian [4] mengenai membandingkan klasifikasi Naive Bayes menggunakan Laplacian dan $K$ Nearest Neighbor $(K-N N)$ untuk seleksi penerima beasiswa. Digunakan dua metode dimaksudkan agar dapat dibandingkan metode mana yang lebih akurat untuk digunakan. Dari hasil penelitian mengungkapkan metode Naive Bayes dengan Laplacian lebih tepat digunakan dibandingkan metode $K$-Nearest Neighbor.

Dalam penelitian ini metode yang digunakan adalah algoritma $K$-Means yang merupakan teknik klastering dan metode $S A W$ dalam mencari penjumlahan bobot pada rating kinerja pada setiap alternatif pada semua atribut Hasil anlisa dapat dilihat dari perhitungan $K$-Means dalam mengelompokkan siswa berprestasi dan metode $S A W$ digunakan dalam menentukan siswa yang berprestasi mana yang layak diberikan beasiswa berprestasi. 
Clustering adalah mengelompokan data, dari hasil observasi kasus ke dalam kelas yang mirip. Perbedaan algoritma clustering dan klasifikasi adalah clustering tidak memiliki class/target/label, jadi bisa dikatakan sebagai unsupervised learning [6]. Clustering bukan klasifikasi karena tidak mengelompokkan kelas data yang telah ada [7].

K-Means adalah salah satu metode yang digunakan dalam pengelompokkan data non-hierarki yang akan membagi data ke dalam dua kelompok atau lebih [8]. KMeans clustering hanya bisa mengerjakan data berupa angka, maka untuk data yang tidak berbentuk angka, maka harus diinisialisasikan dahulu ke dalam bentuk angka [2]. K-Means termasuk ke dalam metode Non-Hierarchy [9].

Sistem pendukung keputusan adalah menggabungkan sumber kecerdasan setiap individu dengan kemampuan dari sebuah komponen untuk dapat memperbaiki mutu dari sebuah keputusan. Sistem pendukung keputusan juga bisa dikatakan sebagai sistem informasi dengan basis komputer untuk manajemen dalam pengambilan keputusan yang dapat menangani masalah-masalah semi terstruktur [3].

Karakteristik utama sistem pendukung keputusan adalah memiliki kemampuan untuk menyelesaikan masalah tidak terstruktur. Dimana, sistem pendukung keputusan merupakan pengembangan lebih lanjut dari sistem manajemen yang terkomputerisasi dan bersifat interaktif dengan pemakainya [10].

Simple Additive Weighting (SAW) adalah metode yang dipakai untuk mencari alternatif yang lebih optimal dari beberapa alternatif dengan kriteria yang telah ditentukan. Metode $S A W$ merupakan metode yang dikenal sebagai metode penjumlahan terbobot dimana dibutuhkan proses normalisasi matriks keputusan kesuatu skala yang dapat diperbandingkan dengan semua alternatif yang ada [11]. Metode ini membantu mengambil keputusan dalam memilih sebuah alternatif yang memberikan hasil paling mendekati tujuan [12].

Prestasi belajar sering diartikan sebagai berapa jauh hasil yang dapat dicapai oleh siswa dalam penyelesaian tugastugas atau penguasaan materi pelajaran yang diperoleh pada jangka waktu tertentu. Untuk memperoleh prestasi yang baik, maka dibutuhkan pengelompokan peserta didik [13].

Saat ini, dalam penentuan siswa yang berprestasi seharusnya tidak dinilai dari aspek akademik saja, namun juga dapat dilihat dari aspek non-akademik juga seperti presensi, ekstrakulikuler, kepribadian, dan kedisplinan. Hal ini dikarenakan kemampuan setiap siswa berbeda. Sehingga siswa dapat dikatakan berprestasi tidak hanya dilihat dari nilai mata pelajaran saja tetapi kemampuan diri juga harus menjadi pendukung penilaian [14].

Pengajuan beasiswa adalah hal yang mempunyai peranan penting dalam kelanjutan studi. Di sekolah banyak sekali beasiswa untuk siswa, baik beasiswa berprestasi maupun kurang mampu [15].

Beasiswa harus diberikan kepada penerima yang berhak mendapatkannya. Akan tetapi, dalam melakukan seleksi pemberian beasiswa, biasanya akan mengalami kesulitan karena banyaknya yang mengajukan beasiswa dan tidak sedikitnya kriteria yang digunakan serta sedikitnya kuota penerima beasiswa setiap periodenya, untuk itu diperlukan sistem pendukung keputusan yang dapat membantu dalam penentuan penerima beasiswa [16].

\section{Metode Penelitian}

\section{A. Alur Proses K-Means}

Penelitian ini memiliki tahapan yang harus dilakukan mulai dari analisa data sampai hasil. Proses $K$-Means dilakukan untuk mengelompokkan siswa yang berprestasi di sekolah. Proses K-Means dapat dilihat pada Gambar 1.

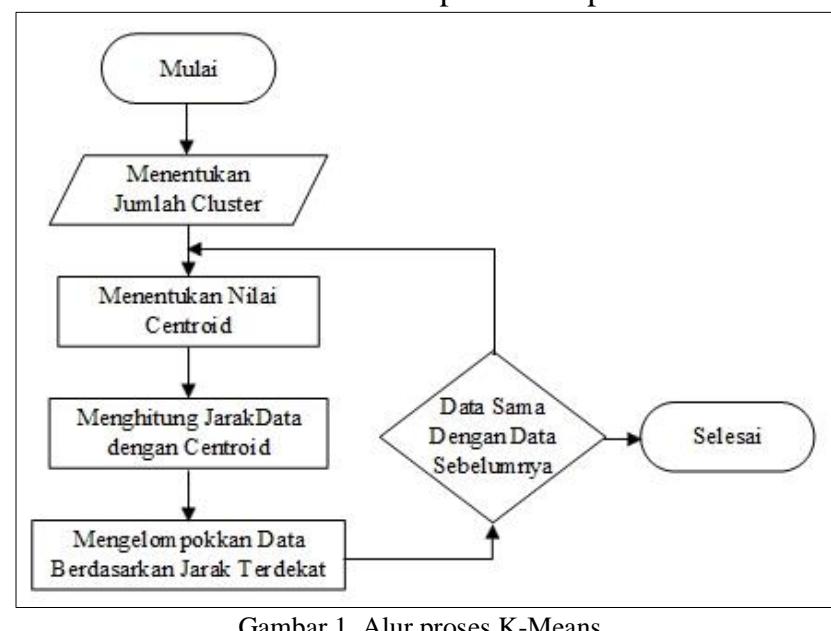

Proses dimulai dari penentuan jumlah klaster, dilanjutkan dengan membangkitkan titik pusat kalster secara acak. Kemudian dilakukan perhitungan jarak menggunakan persamaan Euclidean Distance seperti persamaan 1 :

$$
D_{(C, E)}=\sqrt{\left(E_{1}-C_{1}\right)^{2}}
$$

Setelah jarak diperoleh, maka dikelompokkan data berdasarkan jarak terdekat. Kemudian cari titik pusat klaster yang baru. Bandingkan titik pusat klaster baru dengan yang lama, jika tidak sama, maka proses di ulang kembali.

\section{B. Alur Proses SAW}

Setelah proses $K$-Means selesai maka proses selanjutnya adalah memprediksi siswa yang berhak mendapat beasiswa dengan menggunakan $S A W$. Proses $S A W$ terlihat pada Gambar 2.

Setelah hasil klaster diperoleh, langkah selanjutnya adalah menentukan kriteria dan memberikan nilai bobot pada masing-masing kriteria. Kemudian dilakukan pembuatan matriks keputusan dan dilakukan normalisasi. Pasangkan masing-masing matriks keputusan dengan masing-masing bobot kreiteria. Hitung dan lakukan perangkingan. 


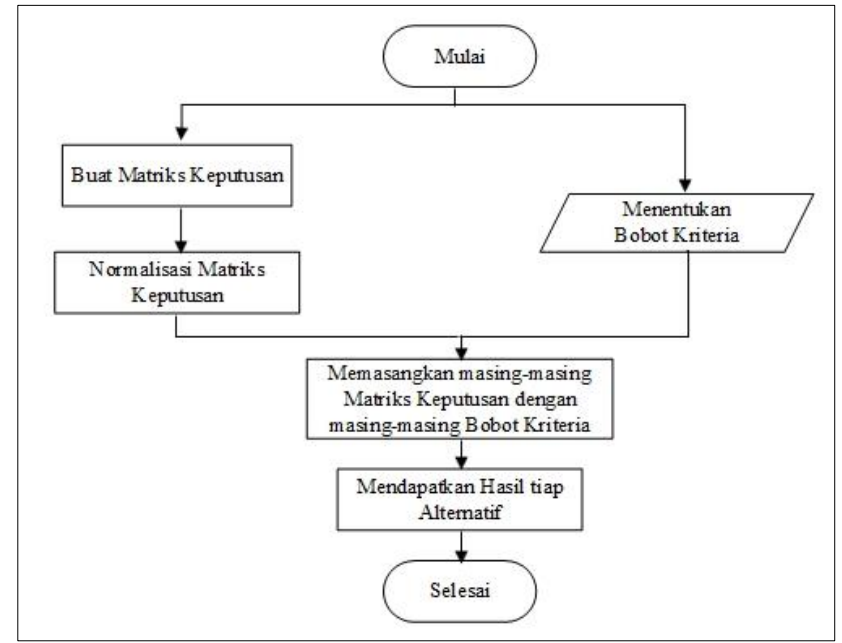

Gambar 2. Alur Proses SAW

\section{HASIL DAN PEMBAHASAN}

\section{A. Pengelompokkan Siswa Berprestasi dengan K-Means}

Penelitian ini menggunakan data siswa kelas XI dan kelas XII yang mengajukan beasiswa prestasi di SMAN 2 Payakumbuh. Data diperoleh dari Wakil Kesiswaan SMAN 2 Payakumbuh berupa nilai rata-rata dari siswa yang mengajukan beasiswa yang diperoleh dari nilai tugas, nilai ulangan harian, nilai UTS dan nilai UAS. Data lain yang diperoleh adalah rangking di kelas, nilai sikap, nilai ekstrakurikuler dan prestasi akademik dan non-akademik.

Data siswa ini yang diperoleh ini akan dikelompokkan untuk mencari siswa yang berprestasi dengan kriteria nilai Tugas (A), nilai UH (B), nilai UTS (C) dan nilai UAS (D). Dari semua kreiteria diatas, maka akan diperoleh Nilai Rata-Rata (E) siswa. Nilai dari masing-masing kriteria diatas diperoleh dengan melakukan wawancara dan memperoleh data langsung dari pihak sekolah.

Terdapat 20 orang siswa yang mengajukan beasiswa prestasi, namun tidak semuanya termasuk siswa yang berprestasi. Maka, diperlukan cara untuk mengelompokkan siswa tersebut, mana yang termasuk siswa yang berprestasi dan mana yang tidak. Data siswa yang digunakan dapat dilihat pada Tabel 1.

Dari Tabel 1 diatas terdapat nilai Rata-rata (E). Nilai ini akan digunakan untuk mengelompokkan data siswa agar diperoleh siswa yang berprestasi. Pengelompokkan dilakukan dengan menggunakan algoritma $K$-Means.

Algoritma $K$-Means dimulai dengan menentukan nilai k yaitu jumlah klaster yang ingin dibentuk. Pada penelitian ini akan dibentuk 2 buah klaster yaitu Siswa Berprestasi (C1) dan Siswa Kurang Berprestasi (C2). Langkah berikutnya adalah menentukan titik pusat untuk masingmasing klaster (centroid) secara random. Untuk C1 diberikan nilai 79 dan untuk C2 diberikan nilai 77. Tahap selanjutnya adalah menghitung jarak masing-masing nilai Rata-rata (E) ke C1 dan C2.

Sehingga dapat diperoleh jarak masing-masing seperti Tabel 2.
TABEL I

Data Siswa Yang Mengajukan Beasiswa

\begin{tabular}{|c|c|c|c|c|c|c|}
\hline No & NIS & $\begin{array}{c}\text { Nilai } \\
\text { Tugas } \\
(\mathbf{A})\end{array}$ & $\begin{array}{c}\text { Nilai } \\
\text { UH } \\
(\mathbf{B})\end{array}$ & $\begin{array}{c}\text { Nilai } \\
\text { UTS } \\
(\mathbf{C})\end{array}$ & $\begin{array}{c}\text { Nilai } \\
\text { UAS } \\
(\mathbf{D})\end{array}$ & $\begin{array}{c}\text { Rata- } \\
\text { rata } \\
(\mathbf{E})\end{array}$ \\
\hline 1 & 1711 & 82 & 91 & 70 & 85 & 82,000 \\
\hline 2 & 1715 & 89 & 68 & 89 & 60 & 76,500 \\
\hline 3 & 1726 & 90 & 85 & 95 & 98 & 92,000 \\
\hline 4 & 1747 & 87 & 80 & 87 & 95 & 87,250 \\
\hline 5 & 1751 & 65 & 75 & 65 & 65 & 67,500 \\
\hline 6 & 1760 & 70 & 75 & 61 & 54 & 65,000 \\
\hline 7 & 1767 & 77 & 76 & 88 & 85 & 81,500 \\
\hline 8 & 1768 & 84 & 82 & 65 & 55 & 71,500 \\
\hline 9 & 1769 & 86 & 87 & 95 & 93 & 90,250 \\
\hline 10 & 1771 & 78 & 78 & 71 & 70 & 74,250 \\
\hline 11 & 1773 & 84 & 88 & 80 & 85 & 84,250 \\
\hline 12 & 1774 & 78 & 77 & 65 & 85 & 76,250 \\
\hline 13 & 1775 & 77 & 87 & 80 & 78 & 80,500 \\
\hline 14 & 1780 & 96 & 98 & 78 & 76 & 87,000 \\
\hline 15 & 1791 & 84 & 81 & 76 & 98 & 84,750 \\
\hline 16 & 1802 & 82 & 98 & 70 & 95 & 86,250 \\
\hline 17 & 1804 & 80 & 88 & 63 & 55 & 71,500 \\
\hline 18 & 1805 & 83 & 71 & 88 & 65 & 76,750 \\
\hline 19 & 1809 & 87 & 68 & 65 & 84 & 76,000 \\
\hline 20 & 1811 & 86 & 76 & 68 & 76 & 76,500 \\
\hline & & & & & & \\
\hline
\end{tabular}

TABEL II

JARAK RATA-RATA (E) KE C1 DAN C2

\begin{tabular}{|c|c|c|c|c|c|}
\hline & C1 & C2 & & C1 & C2 \\
\hline E1 & $\mathbf{3 , 0 0 0}$ & 4,000 & E11 & $\mathbf{5 , 2 5 0}$ & 6,250 \\
\hline E2 & 2,500 & $\mathbf{1 , 5 0 0}$ & $\mathbf{E} 12$ & 2,750 & $\mathbf{1 , 7 5 0}$ \\
\hline E3 & $\mathbf{1 3 , 0 0 0}$ & 14,000 & $\mathbf{E} 13$ & $\mathbf{1 , 5 0 0}$ & 2,500 \\
\hline E4 & $\mathbf{8 , 2 5 0}$ & 9,250 & $\mathbf{E} 14$ & $\mathbf{8 , 0 0 0}$ & 9,000 \\
\hline E5 & 11,500 & $\mathbf{1 0 , 5 0 0}$ & $\mathbf{E} 15$ & $\mathbf{5 , 7 5 0}$ & 6,750 \\
\hline E6 & 14,000 & $\mathbf{1 3 , 0 0 0}$ & $\mathbf{E} 16$ & $\mathbf{7 , 2 5 0}$ & 8,250 \\
\hline E7 & $\mathbf{2 , 5 0 0}$ & 3,500 & E17 & 7,500 & $\mathbf{6 , 5 0 0}$ \\
\hline E8 & 7,500 & $\mathbf{6 , 5 0 0}$ & $\mathbf{E} 18$ & 2,250 & $\mathbf{1 , 2 5 0}$ \\
\hline E9 & $\mathbf{1 1 , 2 5 0}$ & 12,250 & $\mathbf{E} 19$ & 3,000 & $\mathbf{2 , 0 0 0}$ \\
\hline E10 & 4,750 & $\mathbf{3 , 7 5 0}$ & $\mathbf{E 2 0}$ & 2,500 & $\mathbf{1 , 5 0 0}$ \\
\hline
\end{tabular}

Tahapan selanjutnya adalah kelompokkan nilai Ratarata (E) berdasarkan jarak terpendek ke $\mathrm{C} 1$ dan $\mathrm{C} 2$, sehingga dapat diperoleh kelompok nilai Rata-rata (E) sebagai berikut :

Anggota $\mathrm{C} 1$ :

E1, E3, E4, E7, E9, E11, E13, E14, E15, E16

Anggota $\mathrm{C} 2$ :

\section{E2, E5, E6, E8, E10, E12, E17, E18, E19, E20}

Kemudian tentukan nilai centroid baru (C1baru dan C2baru) seperti berikut ini :

$$
\begin{aligned}
& \text { C1 baru }=\frac{\begin{array}{l}
3,000+13,000+8,250+2,500+11,250+ \\
5,250+1,500+8,000+5,750+7,250
\end{array}}{10} \text { C1 baru }=85,575
\end{aligned}
$$




$$
\begin{aligned}
\text { C2baru } & =\frac{\begin{array}{l}
1,500+10,500+13,000+6,500+3,750+ \\
1,750+6,500+1,250+2,000+1,500
\end{array}}{10} \\
\text { C2 baru } & =73,175
\end{aligned}
$$

Setelah memperoleh nilai centroid baru, bandingkan nilai centroid baru dengan centroid lama. Centroid baru tidak sama dengan centroid lama, maka dilakukan perhitungan jarak kembali dengan menggunakan centroid baru. Hasil perhitungan dapat dilihat pada Tabel 3.

TABEL III

JARAK RATA-RATA (E) KE C1BARU DAN C2BARU

\begin{tabular}{|c|c|c|c|c|c|}
\hline & $\mathbf{C 1}$ & $\mathbf{C 2}$ & & $\mathbf{C 1}$ & $\mathbf{C 2}$ \\
\hline E1 & $\mathbf{3 , 5 7 5}$ & 8,825 & $\mathbf{E 1 1}$ & $\mathbf{1 , 3 2 5}$ & 11,075 \\
\hline E2 & 9,075 & $\mathbf{3 , 3 2 5}$ & $\mathbf{E 1 2}$ & 9,325 & $\mathbf{3 , 0 7 5}$ \\
\hline E3 & $\mathbf{6 , 4 2 5}$ & 18,825 & $\mathbf{E} 13$ & $\mathbf{5 , 0 7 5}$ & 7,325 \\
\hline E4 & $\mathbf{1 , 6 7 5}$ & 14,075 & $\mathbf{E} 14$ & $\mathbf{1 , 4 2 5}$ & 13,825 \\
\hline E5 & 18,075 & $\mathbf{5 , 6 7 5}$ & $\mathbf{E} 15$ & $\mathbf{0 , 8 2 5}$ & 11,575 \\
\hline E6 & 20,575 & $\mathbf{8 , 1 7 5}$ & $\mathbf{E 1 6}$ & $\mathbf{0 , 6 7 5}$ & 13,075 \\
\hline E7 & $\mathbf{4 , 0 7 5}$ & 8,325 & $\mathbf{E 1 7}$ & 14,075 & $\mathbf{1 , 6 7 5}$ \\
\hline E8 & 14,075 & $\mathbf{1 , 6 7 5}$ & $\mathbf{E 1 8}$ & 8,825 & $\mathbf{3 , 5 7 5}$ \\
\hline E9 & $\mathbf{4 , 6 7 5}$ & 17,075 & $\mathbf{E 1 9}$ & 9,575 & $\mathbf{2 , 8 2 5}$ \\
\hline E10 & 11,325 & $\mathbf{1 , 0 7 5}$ & $\mathbf{E 2 0}$ & 9,075 & $\mathbf{3 , 3 2 5}$ \\
\hline
\end{tabular}

Kelompokkan kembali nilai Rata-rata (E) berdasarkan jarak terpendek ke C1baru dan C2baru, sehingga dapat diperoleh kelompok nilai Rata-rata (E) sebagai berikut : Anggota $\mathrm{C1}$ :

E1, E3, E4, E7, E9, E11, E13, E14, E15, E16 Anggota $\mathrm{C} 2$ :

E2, E5, E6, E8, E10, E12, E17, E18, E19, E20

Karena tidak terjadi perubahan anggota klaster, maka proses $K$-Means dihentikan. Dari hasil perhitungan $K$ Means, terdapat 10 orang siswa yang masuk kategori siswa berprestasi seperti pada Tabel 4 .

TABEL IIV

KELOMPOK SISWA BERPRESTASI

\begin{tabular}{|c|c|c|c|c|c|c|}
\hline No & NIS & $\begin{array}{c}\text { Nilai } \\
\text { Tugas } \\
(\mathbf{A})\end{array}$ & $\begin{array}{c}\text { Nilai } \\
\text { UH } \\
(\mathbf{B})\end{array}$ & $\begin{array}{c}\text { Nilai } \\
\text { UTS } \\
(\mathbf{C})\end{array}$ & $\begin{array}{c}\text { Nilai } \\
\text { UAS } \\
(\mathbf{D})\end{array}$ & $\begin{array}{c}\text { Rata- } \\
\text { rata } \\
(\mathbf{E})\end{array}$ \\
\hline 1 & 1711 & 82 & 91 & 70 & 85 & 82,000 \\
\hline 2 & 1726 & 90 & 85 & 95 & 98 & 92,000 \\
\hline 3 & 1747 & 87 & 80 & 87 & 95 & 87,250 \\
\hline 4 & 1767 & 77 & 76 & 88 & 85 & 81,500 \\
\hline 5 & 1769 & 86 & 87 & 95 & 93 & 90,250 \\
\hline 6 & 1773 & 84 & 88 & 80 & 85 & 84,250 \\
\hline 7 & 1775 & 77 & 87 & 80 & 78 & 80,500 \\
\hline 8 & 1780 & 96 & 98 & 78 & 76 & 87,000 \\
\hline 9 & 1791 & 84 & 81 & 76 & 98 & 84,750 \\
\hline 10 & 1802 & 82 & 98 & 70 & 95 & 86,250 \\
\hline
\end{tabular}

\section{B. Penentuan Beasiswa Berprestasi dengan SAW}

Hasil pengelompokkan dari K-Means lalu diproses dengan $S A W$ guna untuk mencari siswa yang akan diberi beasiswa berprestasi.
Langkah pertama adalah menentukan kriteria yang akan digunakan dalam proses $S A W$, dimana terdapat 5 kriteria dan langsung ditentukan bobot sesuai dengan tingkat yang telihat pada Tabel 5 .

TABEL V

KRITERIA PENERIMA BEASISWA DAN BOBOTNYA

\begin{tabular}{|c|l|c|}
\hline Kode & \multicolumn{1}{|c|}{ Kriteria } & Bobot \\
\hline K1 & Nilai rata-rata & 0,25 \\
\hline K2 & Rangking & 0,20 \\
\hline K3 & Sikap & 0,15 \\
\hline K4 & Ekstrakurikuler & 0,15 \\
\hline K5 & Prestasi akademik dan non akademik & 0,25 \\
\hline
\end{tabular}

Kriteria nilai rata-rata (K1) merupakan kriteria yang paling penting dalam pengambilan keputusan pemberian beasiswa. Harus dikelompokkan atribut dan diberikan bobot masing-masing atribut seperti pada Tabel 6 .

TABEL VI

ATRIBUT NILAI RATA-RATA (K1) DAN BOBOT

\begin{tabular}{|c|c|c|}
\hline Nilai Rata-rata & Skala Nilai & Bobot \\
\hline $91-100$ & 5 & 1 \\
\hline $81-90$ & 4 & 0,8 \\
\hline $71-80$ & 3 & 0,6 \\
\hline $51-70$ & 2 & 0,5 \\
\hline $0-50$ & 1 & 0,2 \\
\hline
\end{tabular}

Kriteria rangking siswa (K2) merupakan peringkat siswa di kelas. Rangking memiliki 5 atribut dan masing-masing diberikan bobot seperti pada Tabel 7 .

TABEL VII

ATRIBUT RANGKING (K2) DAN BOBOT

\begin{tabular}{|c|c|c|}
\hline Rangking & Skala Nilai & Bobot \\
\hline Sangat Tinggi & 1 & 1 \\
\hline Tinggi & $2-4$ & 0,8 \\
\hline Menengah & $5-7$ & 0,6 \\
\hline Rendah & $8-10$ & 0,5 \\
\hline Sangat Rendah & $\geq 11$ & 0,2 \\
\hline
\end{tabular}

Kriteria sikap (K3) berasal dari nilai sikap siswa yang ada di sekolah, biasanya berupa huruf A,B,C,D,E yang mana didalam huruf tersebut ada nilai yang disklakan dari 5 sampai dengan 1 dan memiliki bobot masing-masingnya, seperti pada Tabel 8.

TABEL VIII

ATRIBUT SIKAP (K3) DAN BOBOT

\begin{tabular}{|c|c|c|}
\hline Sikap & Keterangan & Nilai \\
\hline A & 5 & 1 \\
\hline B & 4 & 0,8 \\
\hline C & 3 & 0,6 \\
\hline D & 2 & 0,4 \\
\hline E & 1 & 0,2 \\
\hline
\end{tabular}

Kriteria ekstrakurikuler (K4) juga sama dengan sikap, nilainya berupa huruf dimana masing-masingnya terdapat skala nilai dan bobot seperti pada Tabel 9 . 
TABEL IX

ATRIBUT EKSTRAKURIKULER (K4) DAN BOBOT

\begin{tabular}{|c|c|c|}
\hline Sikap & Keterangan & Nilai \\
\hline A & 5 & 1 \\
\hline B & 4 & 0,8 \\
\hline C & 3 & 0,6 \\
\hline D & 2 & 0,4 \\
\hline E & 1 & 0,2 \\
\hline
\end{tabular}

Kriteria prestasi akademik dan non akademik (K5) merupakan jumlah prestasi yang diperoleh oleh siswa yang dibuktikan dalam sertifikat tertulis. Terdapat beberapa atribut dan masing-masing bobotnya pada Tabel 10 .

TABEL X

ATRIBUT PRESTASI AKADEMIK DAN NON-AKADEMIK (K5) DAN BOBOT

\begin{tabular}{|c|c|c|}
\hline $\begin{array}{c}\text { Prestasi Akademik dan } \\
\text { Non Akademik }\end{array}$ & Skala Nilai & Bobot \\
\hline Sangat Banyak & $9 \leq$ & 1 \\
\hline Banyak & $6-8$ & 0,75 \\
\hline Cukup & $3-5$ & 0,55 \\
\hline Kurang & $1-2$ & 0,35 \\
\hline Tidak Ada & 0 & 0 \\
\hline
\end{tabular}

Data 10 siswa berpretasi yang akan ditentukan dengan metode $S A W$ lengkap dengan kriteria dari masing-masing siswa, terlihat pada Tabel 11.

TABEL XI

DATA SISWA BEPRESTASI

\begin{tabular}{|c|c|c|c|c|c|c|}
\hline No & NIS & $\begin{array}{c}\text { Rata- } \\
\text { rata } \\
\text { (K1) }\end{array}$ & $\begin{array}{c}\text { Rang } \\
\text { king } \\
\text { (K2) }\end{array}$ & $\begin{array}{c}\text { Sikap } \\
\text { (K3) }\end{array}$ & $\begin{array}{c}\text { Ekskul } \\
\text { (K4) }\end{array}$ & $\begin{array}{c}\text { Prestasi } \\
\text { (K5) }\end{array}$ \\
\hline 1 & 1711 & 82,00 & 3 & A & B & 2 \\
\hline 2 & 1726 & 92,00 & 1 & A & A & 4 \\
\hline 3 & 1747 & 87,25 & 8 & A & B & 0 \\
\hline 4 & 1767 & 81,50 & 6 & B & A & 1 \\
\hline 5 & 1769 & 90,25 & 4 & A & A & 2 \\
\hline 6 & 1773 & 84,25 & 9 & B & A & 0 \\
\hline 7 & 1775 & 80,50 & 4 & A & A & 0 \\
\hline 8 & 1780 & 87,00 & 9 & A & A & 0 \\
\hline 9 & 1791 & 84,75 & 5 & B & B & 2 \\
\hline 10 & 1802 & 86,25 & 6 & B & B & 1 \\
\hline
\end{tabular}

Langkah berikutnya adalah menentukan nilai rating kecocokan pada setiap kriteria seperti pada Tabel 12.

Dari hasil nilai rating kecocokan diatas, maka dapat dibentuk tabel rating kecocokan sebagai berikut, sebelum itu kita lakukan normalisasi matriks X terlebih dahulu.

Selanjutnya dilakukan perhitungan proses normalisasi yang telah didapat dari matriks X. Dilakukan perhitungan normalisasi dari matriks $\mathrm{X}$ :

$$
\begin{aligned}
& R 11=\frac{0,8}{\max (0,8 ; 1 ; 0,8 ; 0,8 ; 1 ; 0,8 ; 0,8 ; 0,8 ; 0,8 ; 0,8)}=\frac{0,8}{1} \\
& R 11=0,8 \\
& R 21=\frac{0,8}{\max (0,8 ; 1 ; 0,5 ; 0,6 ; 0,8 ; 0,5 ; 0,8 ; 0,5 ; 0,6 ; 0,6)}=\frac{0,8}{1}
\end{aligned}
$$

$$
\begin{aligned}
& R 21=0,8 \\
& R 31=\frac{1}{\max (1 ; 1 ; 1 ; 0,8 ; 1 ; 0,8 ; 1 ; 1 ; 0,8 ; 0,8)}=\frac{1}{1} \\
& R 31=1 \\
& R 41=\frac{0,8}{\max (0,8 ; 1 ; 0,8 ; 0,8 ; 1 ; 0,8 ; 0,8 ; 0,8 ; 0,8 ; 0,8)}=\frac{0,8}{1} \\
& R 41=0,8 \\
& R 51=\frac{0,35}{\max (0,35 ; 0,55 ; 0 ; 0,35 ; 0,35 ; 0 ; 0 ; 0 ; 0,35 ; 0,35)} \\
& R 51=\frac{0,35}{0,55}=0,636
\end{aligned}
$$

TABEL XII

RATING KECOCOKAN

\begin{tabular}{|c|c|c|c|c|c|c|}
\hline $\begin{array}{c}\mathbf{N} \\
\mathbf{0}\end{array}$ & NIS & $\begin{array}{c}\text { Rata } \\
\text {-rata } \\
(\mathbf{K 1})\end{array}$ & $\begin{array}{c}\text { Rangkin } \\
\mathbf{g} \\
(\mathbf{K 2})\end{array}$ & $\begin{array}{c}\text { Sika } \\
\mathbf{p} \\
(\mathbf{K 3})\end{array}$ & $\begin{array}{c}\text { Eksku } \\
\mathbf{1} \\
(\mathbf{K 4})\end{array}$ & $\begin{array}{c}\text { Prestas } \\
\mathbf{i} \\
(\mathbf{K 5})\end{array}$ \\
\hline 1 & 1711 & 0,8 & 0,8 & 1 & 0,8 & 0,35 \\
\hline 2 & 1726 & 1 & 1 & 1 & 1 & 0,55 \\
\hline 3 & 1747 & 0,8 & 0,5 & 1 & 0,8 & 0 \\
\hline 4 & 1767 & 0,8 & 0,6 & 0,8 & 1 & 0,35 \\
\hline 5 & 1769 & 1 & 0,8 & 1 & 1 & 0,35 \\
\hline 6 & 1773 & 0,8 & 0,5 & 0,8 & 1 & 0 \\
\hline 7 & 1775 & 0,8 & 0,8 & 1 & 1 & 0 \\
\hline 8 & 1780 & 0,8 & 0,5 & 1 & 1 & 0 \\
\hline 9 & 1791 & 0,8 & 0,6 & 0,8 & 0,8 & 0,35 \\
\hline 10 & 1802 & 0,8 & 0,6 & 0,8 & 0,8 & 0,35 \\
\hline
\end{tabular}

Hasil dari normalisasi diatas lalu dimasukkan matriks ternormalisasi $(\mathrm{R})$ untuk nantinya dilanjutkkan pencarian perangkingannya.

$$
\mathrm{W}=[0,25 ; 0,20 ; 0,15 ; 0,15 ; 0,25] \text {, }
$$

Pencarian perangkingan:

$$
\begin{aligned}
\mathrm{V} 1= & \begin{array}{l}
(0,8) *(0,25)+(0,8) *(0,20)+(1) *(0,15)+ \\
(0,8) *(0,15)+(0,636) *(0,25)
\end{array} \\
\mathrm{V} 1= & 0,2+0,16+0,15+0,12+0,158=0,788 \\
\mathrm{~V} 2= & (1) *(0,25)+(1) *(0,20)+(1) *(0,15)+ \\
& (1) *(0,15)+(1) *(0,25) \\
& 0,25+0,20+0,15+0,15+0,25=1 \\
\mathrm{~V} 2= & (0,8) *(0,25)+(0,5) *(0,20)+(1) *(0,15)+ \\
\mathrm{V} 3= & 0,8) *(0,15)+(0) *(0,25) \\
\mathrm{V} 3= & 0,2+0,1+0,15+0,12+0=0,57 \\
\mathrm{~V} 4= & (0,8) *(0,25)+(0,6) *(0,20)+(0,8) *(0,15)+ \\
& (1)^{*}(0,15)+(0,636) *(0,25) \\
\mathrm{V} 4= & 0,2+0,12+0,12+0,15+0,159=0,749 \\
\mathrm{~V} 5= & (1)^{*}(0,25)+(0,8) *(0,20)+(1) *(0,15)+ \\
& (1)^{*}(0,15)+(0,636) *(0,25) \\
\mathrm{V} 5= & 0,25+0,16+0,15+0,15+0,159=0,869 \\
\mathrm{~V} 6= & (0,8) *(0,25)+(0,5) *(0,20)+(0,8) *(0,15)+
\end{aligned}
$$




$$
\begin{aligned}
& (1)^{*}(0,15)+(0)^{*}(0,25) \\
\mathrm{V} 6= & 0,2+0,1+0,12+0,15+0=0,57 \\
\mathrm{~V} 7= & (0,8)^{*}(0,25)+(0,8)^{*}(0,20)+(1)^{*}(0,15)+ \\
& (1)^{*}(0,15)+(0)^{*}(0,25) \\
\mathrm{V} 7= & 0,2+0,16+0,15+0,15+0=0,66 \\
\mathrm{~V} 8= & (0,8)^{*}(0,25)+(0,5)^{*}(0,20)+(1)^{*}(0,15)+ \\
& (1)^{*}(0,15)+(0)^{*}(0,25) \\
\mathrm{V} 8= & 0,2+0,1+0,15+0,15+0=0,6 \\
\mathrm{~V} 9= & (0,8)^{*}(0,25)+(0,6)^{*}(0,20)+(0,8)^{*}(0,15)+ \\
& (0,8)^{*}(0,15)+(0,636)^{*}(0,25) \\
\mathrm{V} 9= & 0,2+0,12+0,12+0,12+0,159=0,719 \\
\mathrm{~V} 10= & (0,8) *(0,25)+(0,6)^{*}(0,20)+(0,8)^{*}(0,15)+ \\
& (0,8)^{*}(0,15)+(0,636)^{*}(0,25) \\
\mathrm{V} 10= & 0,2+0,12+0,12+0,12+0,159=0,719
\end{aligned}
$$

Berdasarkan perhitungan di atas, perangkingan hasil perhitungan dapat dilihat lebih lengkapnya pada Tabel 13.

. TABEL 13

RANGKING PENERIMA BEASISWA

\begin{tabular}{|c|c|c|c|}
\hline Rangking & NIS & Nilai V & Keputusan \\
\hline 1 & 1726 & 1 & Menerima \\
\hline 2 & 1769 & 0,869 & Menerima \\
\hline 3 & 1711 & 0,788 & Menerima \\
\hline 4 & 1767 & 0,749 & Menerima \\
\hline 5 & 1802 & 0,719 & Menerima \\
\hline 6 & 1791 & 0,719 & Menerima \\
\hline 7 & 1775 & 0,66 & Tidak Menerima \\
\hline 8 & 1780 & 0,6 & Tidak Menerima \\
\hline 9 & 1747 & 0,57 & Tidak Menerima \\
\hline 10 & 1773 & 0,57 & Tidak Menerima \\
\hline
\end{tabular}

Jadi, dari 10 siswa berprestasi, hanya 6 siswa yang akan menerima beasiswa prestasi. Hal ini bisa disesuaikan dengan kuota beasiswa yang akan diberikan oleh sekolah. Dalam hal ini, kuota beasiswa yang tersedia di sekolah hanya 6 beasiswa, maka dari proses perangkingan dengan metode $S A W$, maka yang akan berhak menerima beasiswa adalah siswa yang menempati rangking 1 sampai dengan rangking 6.

\section{Implementasi Aplikasi Penentuan Beasiswa}

Penelitian ini menghasilkan sistem pendukung keputusan yang bisa mengelompokkan siswa berprestasi dan menentukan siswa yang berhak mendapat beasiswa prestasi tersebut.

\begin{tabular}{|c|c|c|c|c|c|}
\hline \multicolumn{6}{|c|}{ Siswa Berpestasi } \\
\hline RATARATA & RANGKING & SIKAP & EKSTRAKTLIKULER & PRESTASI & BERPRESTASI \\
\hline 90.71 & 3 & 5 & 4 & 1 & Berprestasi \\
\hline 91.79 & 1 & 5 & 5 & 3 & Berprestasi \\
\hline 8929 & 8 & 5 & 4 & 0 & Berprestasi \\
\hline 9022 & 5 & 4 & 5 & 1 & Berprestasi \\
\hline 91.43 & 2 & 5 & 5 & 2 & Berprestasi \\
\hline 8857 & 9 & 4 & 5 & 0 & Beprestasi \\
\hline 90.71 & 4 & 5 & 5 & 0 & Berprestasi \\
\hline 8850 & 10 & 5 & 5 & 0 & Berprestasi \\
\hline 89.43 & 7 & 4 & 4 & 2 & Berprestasi \\
\hline 89.86 & 6 & 4 & 4 & 1 & Berprestasi \\
\hline
\end{tabular}

Sistem pendukung keputusan dibuat dengan memakai bahasa pemrograman PHP dan dibantu dengan basis data MySQL. Sistem pendukung keputusan ini digunakan oleh Wakil Kesiswaan yang ada di sekolah.

Halaman utama yang bisa diakses adalah halaman Login, dimana Wakil Kesiswaan harus memasukkan username dan password, seperti pada Gambar 3.

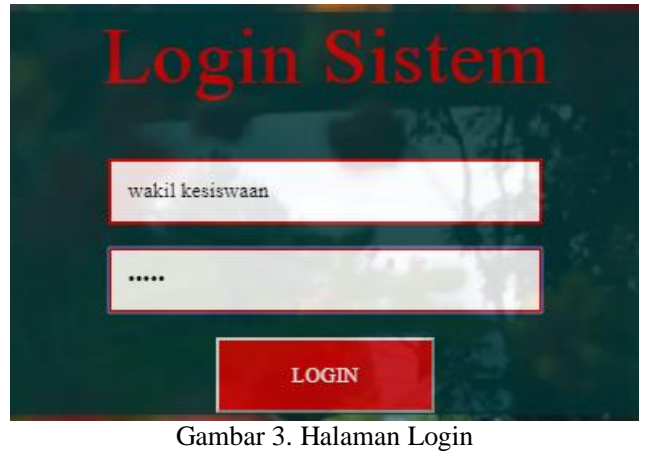

Setelah berhasil login, Wakil Kesiswaan dapat memasukkan data siswa yang mengajukan beasiswa untuk dapat dikelompokkan dengan algoritma K-Means, sehingga diperoleh Siswa yang Berprestasi. Data siswa berprestasi yang dimasukkan dapat dilihat pada Gambar 4 .

Gambar 4. Data Siswa Berprestasi

Setelah proses K-Means selesai, dilakukan proses perangkingan dengan metode $S A W$, untuk memperoleh siswa berprestasi yang berhak mendapat beasiswa prestasi. Hasil perangkingan dapat dilihat pada Gambar 5.

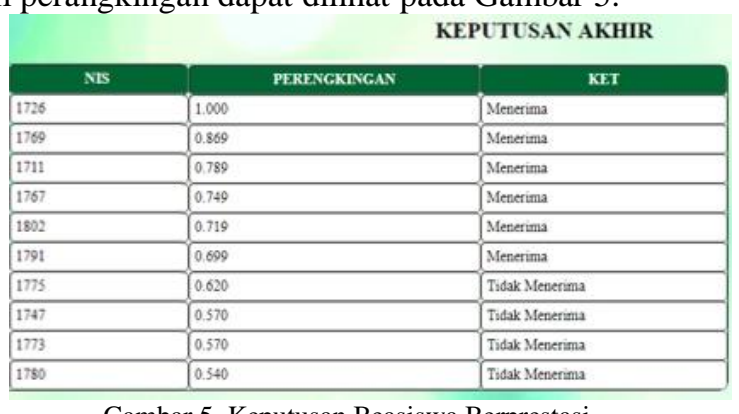

Gambar 5. Keputusan Beasiswa Berprestasi

\section{KESIMPULAN}

Dari penelitian yang sudah dilakukan, aplikasi yang dihasilkan dari penelitian ini sudah dilakukan pengujian dengan metode black box untuk memeriksa fungsional dari aplikasi yang dihasilkan. Pengujian dilakukan oleh wakil kesiswaan SMAN 2 Payakumbuh dengan cara menjalankan aplikasi ini dan menyatakan hasil aplikasi ini sesuai dengan proses yang ada di sekolah tersebut. Wakil kesiswaan SMAN 2 Payakumbuh juga menyatakan pihak sekolah akan sangat terbantu jika aplikasi ini bisa digunakan di SMAN 2 Payakumbuh. 
Jadi, dari pernyataan diatas dapat diambil kesimpulan bahwa aplikasi ini dapat memberi kemudahan bagi pihak sekolah dalam pengelompokkan siswa yang berprestasi dengan menggunakan data mining algoritma K-Means yang terdiri dari nilai tugas, nilai UH, nilai UTS, dan nilai UAS untuk mendapatkan nilai Rata-Rata. Analisis menggunakan metode $S A W$ dengan kriteria nilai rata-rata yang dikelompokkan dalam skala nilai 1-5, rangking yang dikelompokkan dengan skala sangat tinggi, menengah, rendah dan sangat rendah, sikap dengan skala nilai A-E, dan ekstrakurikuler dengan nilai A-E, serta prestasi akademik dan non akademik dengan sangat banyak, banyak, cukup, kurang dan tidak ada. Hasil Pengolahan data dengan menggunakan kedua metode menghasilkan keputusan Menerima dan Tidak Menerima.

\section{REFERENSI}

[1] M. Muslihudin and D. Hartini, "Perancangan Sistem Pendukung Pengambilan Keputusan Untuk Penerimaan Beasiswa Di SMA PGRI 1 Talang Padang Dengan Model Fuzzy Multiple Attribute Menggunakan Metode Simple Additive Weighting (SAW)," $J$. TAM (Technology Accept. Model., vol. 4, pp. 34-40, 2017.

[2] M. L. Sibuea and A. Safta, "Pemetaan Siswa Berprestasi Menggunakan Metode K-Means Clustring," JURTEKSI, vol. 4, no. 1, pp. 85-92, 2017.

[3] T. Susilowati, S. Suyono, and E. S. Suranti, "Sistem Pendukung Keputusan Untuk Menentukan Penerima Beasiswa Pada SMAN 1 Bangunrejo Menggunakan Metode SAW," in Seminar Nasional Inovasi Teknologi, 2017, vol. 1, no. 1, pp. 151-158.

[4] D. Rahmawati, A. B. Setiawan, and F. R. Hariri, "ANALISA PERBANDINGAN METODE KLASIFIKASI NAIVE BAYES DENGAN LAPLACIAN DAN K-NEAREST NEIGHTBOR (K-NN) PADA SELEKSI PENERIMA BEASISWA."

[5] R. Gunawan, "Implementasi Data Mining Untuk Memprediksi Prestasi Siswa Berdasarkan Status Sosial Dan Kedisiplinan Pada Smk Bayu Pertiwi Menggunakan Metode Regresi Linier Berganda," J. SAINTIKOM (Jurnal Sains Manaj. Inform. dan Komputer), vol. 17, no. 2, pp. 175-183, 2018.

[6] N. Butarbutar, A. P. Windarto, D. Hartama, and S. Solikhun, "Komparasi Kinerja Algoritma Fuzzy C-Means Dan K-Means
Dalam Pengelompokan Data Siswa Berdasarkan Prestasi Nilai Akademik Siswa," Jurasik (Jurnal Ris. Sist. Inf. dan Tek. Inform., vol. 1, no. 1, pp. 46-55, 2017.

[7] H. Priyatman, F. Sajid, and D. Haldivany, "Klasterisasi Menggunakan Algoritma K-Means Clustering untuk Memprediksi Waktu Kelulusan Mahasiswa," JEPIN (Jurnal Edukasi dan Penelit. Inform., vol. 5, no. 1, pp. 62-66, 2019.

[8] E. Prasetyo, "Data Mining konsep dan Aplikasi menggunakan MATLAB," Yogyakarta Andi, 2012.

[9] D. E. Putri, "Metode Non Hierarchy Algoritma K-Means Dalam Mengelompokkan Tingkat Kelarisan Barang (Studi Kasus: Koperasi Keluarga Besar Semen Padang)," Pros. Senat., vol. 1, 2015.

[10] S. Eniyati, "Perancangan Sistem Pendukung Pengambilan Keputusan untuk Penerimaan Beasiswa dengan Metode SAW (Simple Additive Weighting)," Dinamik, vol. 16, no. 2, 2011.

[11] A. Topadang and T. R. Tulili, "SISTEM PENDUKUNG KEPUTUSAN PEMILIHAN SISWA BERPRESTASI DI JEMAAT MORIA SAMARINDA SEBERANG DENGAN METODE SIMPLE ADDITIVE WEIGTHTING," J. Sains Terap. Teknol. Inf., vol. 10, no. 2, pp. 5-9, 2019.

[12] F. Frieyadie and others, "Penggunaan Metode Simple Additive Weighting Penentuan Kelayakan Pemberian Beasiswa untuk Siswa Berprestasi," JITK (Jurnal Ilmu Pengetah. Dan Teknol. Komputer), vol. 3, no. 1, pp. 17-22, 2017.

[13] N. Jannah and T. Yulianto, "Mengelompokkan Siswa Berprestasi Akademik dengan Menggunakan Metode K Means Kelas VII MTs Hidayatul Mubtadi'in Pancoran Kadur," ZetaMath J., vol. 2, no. 2, pp. 41-45, 2016

[14] J. Irjaya Kartika, E. Santoso, and Sutrisno, "Penentuan Siswa Berprestasi Menggunakan Metode K-Nearest Neighbor dan Weighted Product (Studi Kasus: SMP Negeri 3 Mejayan)," $J$. Pengemb. Teknol. Inf. dan Ilmu Komput., vol. 2548, p. 964X, 2017.

[15] J. Parhusip, D. O. Enny, and T. R. Jekwoso, "APLIKASI SISTEM PENUNJANG KEPUTUSAN PEMILIHAN SISWA BERPRESTASI DI SMP NEGERI-8 PALANGKA RAYA," $J$. Inform., vol. 17, no. 1, pp. 32-48, 2017.

[16] B. Basri, "METODE WEIGHTD PRODUCT (WP) DALAM SISTEM PENDUKUNG KEPUTUSAN PENERIMAAN BEASISWA PRESTASI," J. INSYPRO (Information Syst. Process., vol. 2, no. 1, 2017. 